\title{
QUALITY ASSESSMENT OF TANDEM-X DEMs USING AIRBORNE LiDAR, PHOTOGRAMMETRY AND ICESat ELEVATION DATA
}

\author{
Y. S. Rao ${ }^{\text {a }}$, Rinki Deo ${ }^{\text {a }}$ J. Nalini ${ }^{\text {b }}$, Abhijit M Pillai ${ }^{\text {, }}$ S. Muralikrishnan ${ }^{\text {b }, ~ V . ~ K . ~ D a d h w a l ~}{ }^{\text {b }}$ \\ ${ }^{a}$ CSRE, Indian Institute of Technology Bombay, Mumbai-400076, India - (ysrao, rinkideo1@iitb.ac.in) \\ ${ }^{\mathrm{b}}$ National Remote Sensing Centre, ISRO, Hyderabad-500037, India - (nalini_j, abhijitmadhusudan_p, \\ muralikrishnan_s)@nrsc.gov.in, dadhwalvk@hotmail.com
}

Commission VIII, WG VIII/1

KEY WORDS: TanDEM-X, DEM, Accuracy, InSAR, LiDAR, ICESat, photogrammetry

\begin{abstract}
:
TanDEM-X mission has been acquiring InSAR data to produce high resolution global DEM with greater vertical accuracy since 2010. In this study, TanDEM-X CoSSC data were processed to produce DEMs at $6 \mathrm{~m}$ spatial resolution for two test areas of India. The generated DEMs were compared with DEMs available from airborne LiDAR, photogrammetry, SRTM and ICESat elevation point data. The first test site is in Bihar state of India with almost flat terrain and sparse vegetation cover and the second test site is around Godavari river in Andhra Pradesh (A.P.) state of India with flat to moderate hilly terrain. The quality of the DEMs in these two test sites has been specified in terms of most widely used accuracy measures viz. mean, standard deviation, skew and RMSE. The TanDEM-X DEM over Bihar test area gives 5.0 m RMSE by taking airborne LiDAR data as reference. With ICESat elevation data available at 9000 point locations, RMSE of $5.9 \mathrm{~m}$ is obtained. Similarly, TanDEM-X DEM for Godavari area was compared with high resolution aerial photogrammetric DEM and SRTM DEM and found RMSE of $5.3 \mathrm{~m}$ and $7.5 \mathrm{~m}$ respectively. When compared with ICESat elevation data at several point location and also the same point locations of photogrammetric DEM and SRTM, the RMS errors are $4.1 \mathrm{~m}, 3.5 \mathrm{~m}$ and $4.3 \mathrm{~m}$ respectively. DEMs were also compared for open-pit coal mining area where elevation changes from $-147 \mathrm{~m}$ to $189 \mathrm{~m}$. X- and Y-profiles of all DEMs were also compared to see their trend and differences.
\end{abstract}

\section{INTRODUCTION}

Digital Elevation Models (DEMs) and its derived parameters play an important role directly or indirectly in many scientific applications including hydrology, geomorphology, ecology and other disciplines. In all these applications, the quality of DEM determines the quality of the output (Carlisle, 2002). Numerous DEM generation techniques like conventional geodesy measurements, photogrammetric and remote sensing methods with different scale and accuracy levels are used for DEM generation. Errors of DEM can propagate throughout the data processing in investigations they are used in and can adversely affect the accuracy of its outcome (Wechsler, 2007). Hence, it is very important to understand the quality of a DEM to be used for certain applications.

Among all the remote sensing techniques for DEM generation, InSAR has an upper hand and has proved to be an efficient tool to generate high precision DEM because of its wide and continuous coverage, high precision, cost effectiveness and feasibility of recording data in all weather conditions (Rosen et al., 2000). InSAR has been extensively used to map earth's topography with the implementation of several spaceborne repeat-pass sensors (Massonnet and Feigl, 1998). However, from several studies it has been observed that the height accuracy from repeat pass interferometry is influenced by temporal decorrelation in certain regions, especially in heavily vegetated areas, even with the relatively short time separation of one day as in the case of ERS- $1 \& 2$ tandem data. SRTM launched in February 2000 demonstrated for the first time the single-pass InSAR technology for quality interferogram formation by reduction of temporal decorrelation and generating more accurate global topographic maps from space (Toutin and Gray, 2000, Zhou et al., 2009, Bamler et al., 2003). The coverage of this SRTM DEM was principally limited to a latitude range from $56^{\circ} \mathrm{S}$ to $60^{\circ} \mathrm{N}$ due to the inclined orbit of the Space Shuttle and its mapping geometry. Moreover, X-band
SRTM DEM has wide gaps at lower latitudes and the C-band DEMs are available to the public at an artificially impaired spatial resolution (DTED-1 specifications).

There are many applications which require both an extended latitudinal coverage and an improved accuracy comparable to DEMs generated by high resolution airborne radar systems (Hajnsek and Busch, 2010). TanDEM-X is the first ever spaceborne mission in which interferometric data are acquired in bistatic mode. Launched in June 2010, it has been acquiring data to generate a consistent global DEM equalling HRTI-3 specification i.e. $10 \mathrm{~m}$ absolute and $2 \mathrm{~m}$ relative height accuracy at $12 \mathrm{~m}$ horizontal resolution (Krieger et al., 2007, Schulze et al. 2014). The global DEM is being generated by mosaicking and calibrating several DEMs acquired in different passes to achieve this height accuracy (Gruber et al., 2012a). The quality is continuously monitored in acquisition as well as in processing phase (Brautigam et al., 2012). In this paper the quality of TanDEM-X DEMs generated using single pair acquisition raw DEM has been assessed based on highly accurate airborne LiDAR DEM, digital aerial photogrammetry stereo DEM and ICESat elevation points as reference for two test sites of India. Section 2 gives various data sets used for DEM generation and section 3 presents test area used for DEM evaluation. Methodology for data processing is given in section 4 and analysis of data for the evaluation of DEMs is given in section 5 .

\section{DATA SETS}

TanDEM-X data is obtained over Bihar in northern India and Godavari region of undivided Andhra Pradesh state in the southern part of India through announcement of opportunity from DLR, Germany. These test sites have been selected in view of the availability of high accurate LiDAR and digital photogrammetric DEMs. The dates of acquisition and various scene parameters are given in the Table 1 . Several TanDEM-X 
scenes were obtained over Godavari test area to reduce the effect of layover and shadow regions occurring in hilly terrain. Bihar area is relatively flat and produce less geometrical distortions in TanDEM-X images. For such type of areas, many scenes are not required for accurate DEM generation. Hence, only one data set has been selected for this study.

Godavari test area is relatively undulating terrain with isolated hills. As the area consists of open-pit coal mine area with large elevation, TanDEM-X data with ascending and descending passes were also obtained. For all the scenes, incidence angles are almost same. The height ambiguity which is related to perpendicular baseline is low for all scenes except descending pass scene on Jan. 10, 2013. On Sept. 5, 2012 image, dark patch at the right corner of the image is seen due to heavy rainfall during the acquisition period. TanDEM-X data has spatial resolution of $2.71 \mathrm{~m}$ in ground range and $3.92 \mathrm{~m}$ in azimuth.

\begin{tabular}{|l|l|l|l|c|l|}
\hline Test Area & $\begin{array}{l}\text { Date of } \\
\text { Acquisition } \\
\text { DD:MM:YY } \\
\text { YY }\end{array}$ & Pass & $\begin{array}{l}\text { Inci- } \\
\text { dence } \\
\text { Angle }\end{array}$ & $\begin{array}{c}\mathrm{B}_{\text {perp }} \\
(\mathrm{m})\end{array}$ & $\begin{array}{l}\text { Height } \\
\text { Ambi- } \\
\text { guity (m) }\end{array}$ \\
\hline Bihar & $12-09-2012$ & Asc. & 41.4 & 208.2 & 32.7 \\
\hline Godavari & $04-07-2011$ & Asc. & 40.6 & 150.2 & 44.9 \\
\hline Godavari & $29-01-2012$ & Asc. & 40.6 & 68.7 & 98.1 \\
\hline Coal Mine & $05-09-2012$ & Asc. & 39.3 & 211.7 & 30.0 \\
\hline Coal Mine & $10-01-2013$ & Dsc. & 39.3 & 35.7 & 189.1 \\
\hline
\end{tabular}

Table 1. TanDEM-X datasets used for DEM generation.

LiDAR data is obtained over Bihar regions using the Leica ALS50 airborne laser scanner operating at $1064 \mathrm{~nm}$ wavelength. The system was mounted in Beechcraft Super King Air B-200 aircraft and flew over this area in Nov. 2009. The accuracy of the system is 0.3 meters in horizontal and 0.25 meters in vertical after post processing. The system can detect up to 3 targets for each outbound pulse and can determine ground elevation even under trees. The DEM generated for this area is at $2 \mathrm{~m}$ spatial resolution.

Aerial photogrammetric stereo DEM was obtained over Godavari test areas in Jan. 2012 with UtraCam-D Large Format Digital Camera (LFDC) from Vexcel Corporation. The camera obtains images in the form of frames of size $11500 \times 7500$ pixels with pixel size of $9 \mu \mathrm{m}(30 \mathrm{~cm} \mathrm{GSD}$ at $3 \mathrm{~km}$ flight altitude) and geometrical accuracy of $2 \mu \mathrm{m}$. The accuracy of the system is 0.3 meters in horizontal and 0.50 meters in vertical after post processing The DEM products were developed for $2 \mathrm{~m}$ spatial resolution.

\section{TEST SITES}

Bihar test site is mostly agriculture area with isolated trees. Major towns in the area covered by TanDEM-X scene as shown in Figure 1 are Dharbanga, Basaha Mirzapore, Bastwara in the middle of the scene, Kishanpur, Ratras, Baheri, Balipur Parsuram, Kariyan and parts of Samastipur district in the south and in the north, Nikashi and Paigamberpur. As the area is flood prone for many times, high resolution airborne LiDAR data was also acquired over this area. Elevation in this area from SRTM DEM varies from $-29 \mathrm{~m}$ to $7 \mathrm{~m}$ with respect to WGS84 ellipsoid.

Godavari test site is in the southern part of India in the undivided Andhra Pradesh state. It has varying land covers from reserved forest to agriculture lands. Hilly terrain with thick forest is confined to the southern part of July 4, 2011 and Jan. 29, 2012 TanDEM-X scenes as shown in Figure 2. Major towns in the scene are Bhadrachalam in the middle, Upparu in the south and Aswapuram in the north. The elevation in the scene varies from $-57 \mathrm{~m}$ in flat areas to $585 \mathrm{~m}$ in the hilly terrain with respect to WGS84 ellipsoid. Just above the scene, Manuguru town with open-pit coal mine area, Bandaruguadam and Cherla towns are covered in the TanDEM-X images acquired on Sep. 9, 2012 and Jan 10, 2013. Elevation in the scene varies from $50 \mathrm{~m}$ to $880 \mathrm{~m}$. As the mining continued for 13 years since SRTM DEM availability, lowest elevation in the area obtained with TanDEM-X data is $-147 \mathrm{~m}$.

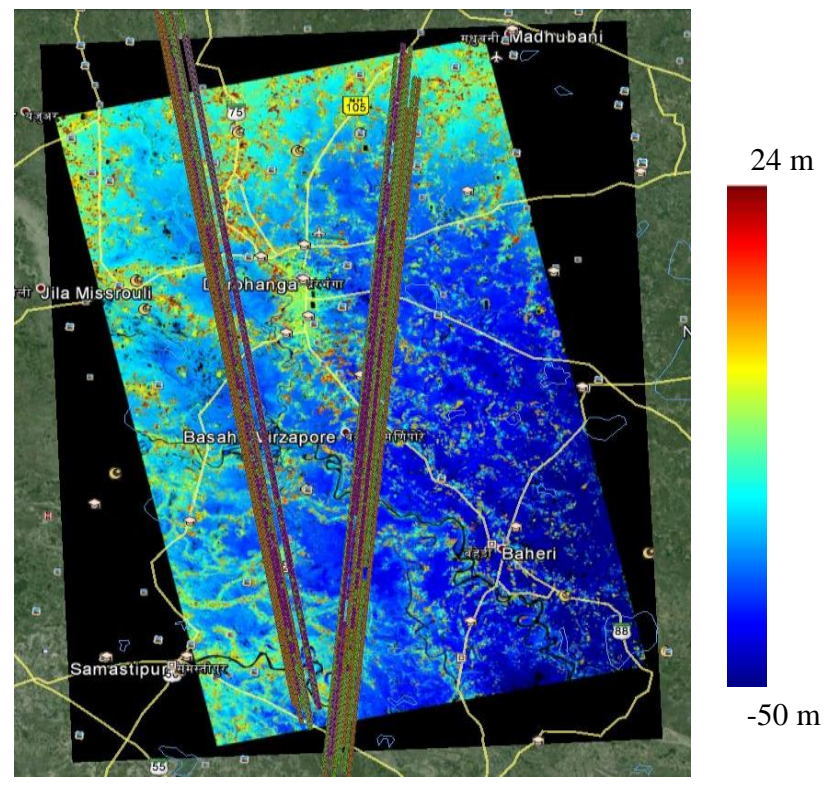

Figure 1. Bihar test area coverage on Google map showing towns, ICESat passes and TanDEM-X DEM in colour scale.

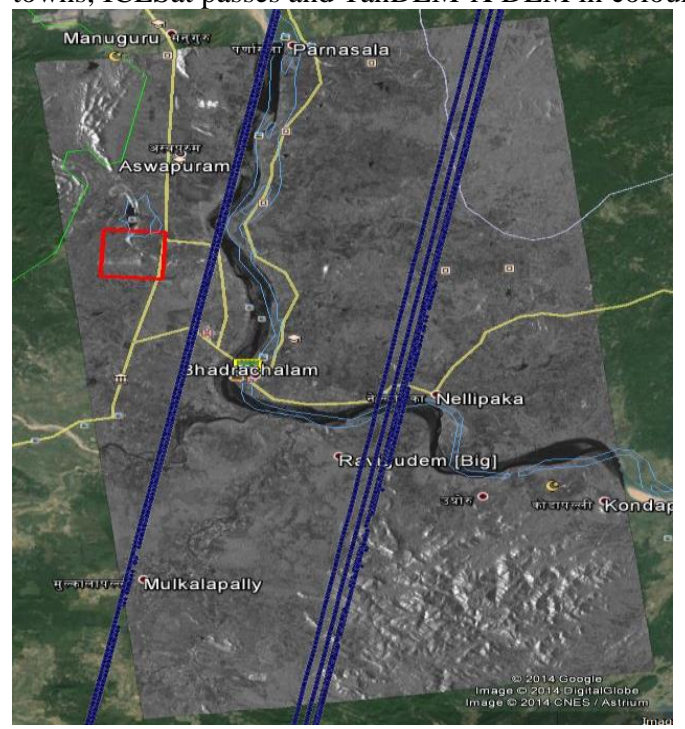

Figure 2. Godavari test area coverage and TanDEM-X amplitude image of Jan 29, 2012 on Google map showing DEM evaluation area in red square.

\section{DATA PROCESSING FOR DEM GENERATION}

\subsection{TanDEM-X, LiDAR and LFDC DEMs}

SARScape software has been used to process TanDEM-X Coregistered Single Look Slant Range Complex (CoSSC) data 
to generate DEM using the work flow as shown in Figure 3. Using the CoSSC data, interferogram was generated and then multilooked 2 times in range and azimuth to reduce the phase noise in interferogram. Raw DEM was generated with spatial resolution of $6 \mathrm{~m}$. The so called 'raw DEM' explains that the DEM is not calibrated for baseline and elevation offset with known GCP points (González et al. 2012). Although global DEM is generated at $12 \mathrm{~m}$ spatial resolution, local DEMs can be generated at $6 \mathrm{~m}$ resolution with the same data. SRTM DEM is generally used to simulate interferogram phase related to topography of the terrain. The phase is subtracted from the interferogram phase to obtain differential interferogram. The differential interferogram is filtered and its phase is unwrapped. The unwrapped phase is added back to the simulated topographic phase obtained using SRTM DEM and is converted to height. If the SRTM DEM is not available, topographic interferogram is directly unwrapped and the unwrapped phase is converted to height. The advantage in generating differential interferogram is to make phase unwrapping task easy and reduce errors involved in phase unwrapping.

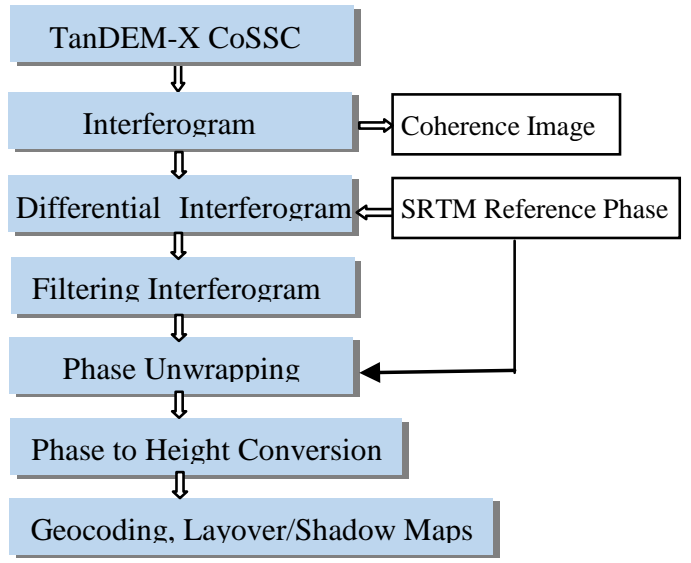

Figure 3. TanDEM-X inteferometric processing work flow.

LiDAR and Digital Photogrammetric Stereo DEM are produced with $2 \mathrm{~m}$ resolution using the post processing software. For analysis, these DEMs have been resampled to the same projection (geographic lat/long, WGS84) and pixel size of TanDEM-X DEM.

\subsection{Bihar DEMs}

TanDEM-X DEM generated for Bihar is shown in Figure 1 in colour scale. The common part of LiDAR and TanDEM-X DEM over Bihar area is extracted for comparison. The LiDAR DEM is in UTM projection and is converted to geographic latitude/longitude projection to match with TanDEM-X DEM. The available LiDAR DEMs have two types. 1) Without correcting surface features i.e. surface DEM and 2) DEM after removing vegetation heights. In our evaluation of TanDEM-X DEM, we used LiDAR DEM without applying vegetation corrections. After bringing the DEMs to the same projection, offset between two DEMs was cross checked by overlaying the corresponding intensity images and also by comparing DEM profiles in $\mathrm{X}$ - and Y-direction.

\subsection{Godavari DEMs}

Digital photogrammetric (LFDC) DEM has been used for the evaluation of TanDEM-X DEM for this test area. The DEM is in UTM projection referenced to geoid i.e mean sea level heights. It is converted to WGS84 ellipsoid to match with
TanDEM-X DEMs and the pixel spacing LFDC DEM is brought to $6 \mathrm{~m}$ from $2 \mathrm{~m}$ by averaging pixels. As the LFDC DEM for the area is in small tiles, we took a small part of digital photogrammetric DEM for comparison with TanDEM-X DEM. The small part is shown in Figure 2 and covers only $4.5 \mathrm{~km} \mathrm{x}$ $4.3 \mathrm{~km}$ area (756 pixels by 724 lines) of $30 \mathrm{~km} \times 50 \mathrm{~km}$ full TanDEM-X scene.

Similarly open-pit coal mine area is also extracted from TanDEM-X DEM for comparison with digital photogrammetric DEM. The extracted part is shown in Figure 8.

\subsection{Statistics for TanDEM-X DEM Evaluation}

The quality of DEM is assessed by taking the difference between TanDEM-X DEM and reference DEM. According to USGS, reference DEM should be at least one order better than the DEM to be evaluated for absolute assessment. The statistical quality measures generally used in evaluation is standard deviation or RMSE and RMSE with $90 \%$ of data so that outliers can be eliminated. RMSE is a valuable parameter to know the true elevation expected within a range, but it does not provide accurate value of each pixel's true elevation. The mean error and standard deviation are also considered for error analysis (Wechsler et al. 2003). In our analysis, min, max, mean, standard deviation, skew, RMSE and 90\% RMSE have been used for the evaluation of TanDEM-X DEMs.

\section{EVALUATION OF DEMS}

\subsection{Bihar DEM}

TanDEM-X DEM with ICESat passes are shown in Figure 1. The difference DEM (TanDEM-X DEM minus airborne LiDAR) is shown in Figure 4. The statistics from elevation difference between TanDEM-X DEM and aerial LiDAR DEM is given in Table 2. Similarly, the statistics for ICESat elevation data points and corresponding to the same point locations in SRTM DEM and LiDAR DEM are given in Table 3. Although the area is flat, the statistics for slope values below and above $20 \%$ slope are also given in Table 2. Before the calculation of statistics, a mask is applied on DEM with Height Error Map (HEM) value greater than $4 \mathrm{~m}$ to mask out water and some vegetation covered areas with low coherence. The $4 \mathrm{~m}$ threshold values is selected based on $95 \%$ of total Height Error Map (HEM) value distribution.

\begin{tabular}{|l|l|l|l|l|l|l|}
\hline $\begin{array}{l}\text { Ref.Data } \\
\text { type }\end{array}$ & Min & Max & Mean & Skew & $\begin{array}{l}\text { Std } \\
\text { dev }\end{array}$ & RMSE \\
\hline LiDAR & -66.7 & 43.6 & 4.52 & -1.04 & 2.06 & 4.97 \\
\hline$<20 \%$ & -66.7 & 42.5 & 4.48 & -1.61 & 1.66 & 4.77 \\
\hline$>20 \%$ & -60.7 & 22.9 & 5.15 & -0.61 & 3.66 & 6.32 \\
\hline SRTM & -41.5 & 36.1 & 0.44 & 0.55 & 2.78 & 2.80 \\
\hline
\end{tabular}

Table 2. Elevation difference statistics for Bihar test site.

The difference image (Figure 4) shows decreasing trend in difference from left to right. Light blue colour shows negative values (i.e. LiDAR values are higher than TanDEM-X) and red shows positive differences. Similar pattern is observed with SRTM data, but RMSE value $(2.8 \mathrm{~m})$ is less than LiDAR DEM as shown in Table 2. Mean value is close to zero with SRTM as reference. Differences in tree and building height cause high RMSE value. However, the error is within specified limit of TanDEM-X mission specification i.e. $10 \mathrm{~m}$. With point data at 9000 locations, min and max values are reduced and RMSE 
error is similar to the values obtained using raster LiDAR data. With calibrated TanDEM-X DEMs, Gruber et al. (2012b) obtained better accuracy.

\begin{tabular}{|l|l|l|l|l|l|l|}
\hline $\begin{array}{l}\text { Ref.Data } \\
\text { type }\end{array}$ & Min & Max & Mean & Skew & $\begin{array}{l}\text { Std } \\
\text { dev }\end{array}$ & RMSE \\
\hline LIDAR & -22.3 & 25.4 & 4.90 & 0.67 & 2.36 & 5.43 \\
\hline SRTM & -12.6 & 21.0 & 0.95 & 1.06 & 2.85 & 2.30 \\
\hline ICESAT & -19.4 & 25.5 & 5.30 & -0.27 & 2.60 & 5.89 \\
\hline
\end{tabular}

Table 3. Statistics with elevation difference between TanDEM$\mathrm{X}$ and other reference data at 9000 selected point locations for Bihar test site.

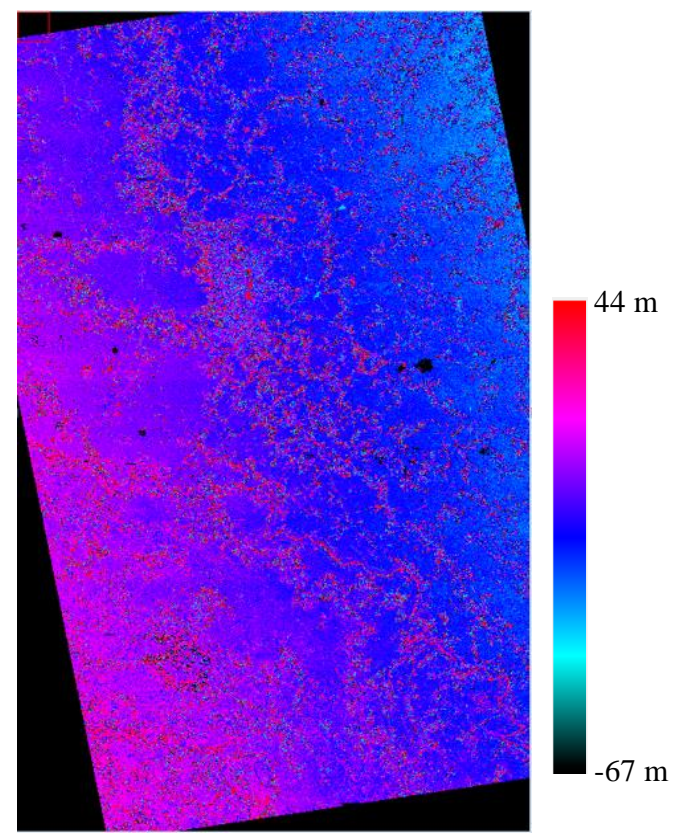

Figure 4. Difference between TanDEM-X DEM and LiDAR DEM shown in colours. Black to cyan to Light blue show negative values and dark blue to red shows positive values.

At a particular location of Bihar DEM, X- and Y-profile plots for airborne LiDAR and TanDEM-X DEM are shown in Figure 5 for comparison of DEM values. Although the elevation trend is similar for both DEMs, LiDAR elevation is less than that of TanDEM-X by $4 \mathrm{~m}$. The differences are to be investigated through ground-truth DGPS data as our TanDEM-X DEM is not calibrated for constant offsets.

\subsection{Godavari DEM}

A small part of full scene of TanDEM-X DEM on Jan. 29, 2012 is shown in Figure 6 along with difference image in colour scale. Statistics related to difference image (Figure 6(b)) is given in Table 4 for Jan. 29, 2012 DEM and the Table 5 show the statistics using TanDEM-X DEM on July 4, 2011 and LFDC DEM. RMSE is about 5.0 m with Jan 29, 2012 DEM and it is $2.64 \mathrm{~m}$ with July 4, 2011 DEM. The difference is due to height ambiguity difference between two acquisitions as given in Table 1. Difference between ICESat elevation and TanDEM$X$ DEM values at several locations and also the differences between TanDEM-X DEM and SRTM, LFDC at the same point locations are calculated and given in Table 6. The differences with ICESat data are similar to those obtained with LFDC data. With SRTM DEM, differences are slightly higher than ICESat data, except for mean value. As the LFDC image is very small, the number of ICESat points in the LFDC image is only 413. For the calculation of statistics, we used fused DEM of TanDEM-X DEMs of July 4, 2011 and Jan. 29, 2012.
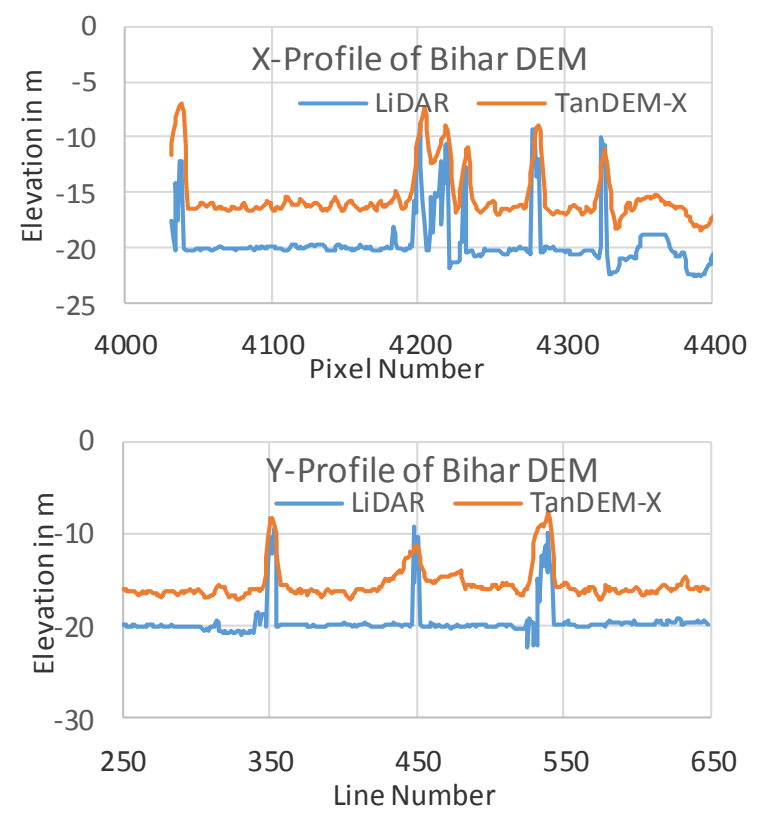

Figure 5. Elevation trend for airborne LiDAR and TanDEM-X DEMs for Bihar test area at a particular location in X-direction and Y-direction of the DEM.

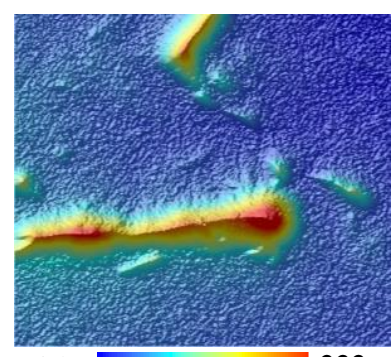

$-15 \mathrm{~m}$ (a)

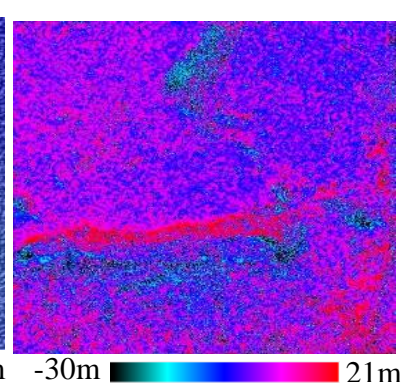

(b)
Figure 6. (a) TanDEM-X DEM of a small region from 29-012012 data and (b) Difference between TanDEM-X and aerial photogrammetric DEM.

\begin{tabular}{|l|c|c|c|c|l|l|l|}
\hline $\begin{array}{l}\text { Ref.Data } \\
\text { type }\end{array}$ & Min & Max & Mean & Skew & $\begin{array}{l}\text { Std } \\
\text { dev }\end{array}$ & RMSE & $\begin{array}{l}90 \% \\
\text { RMSE }\end{array}$ \\
\hline LFDC & -30.7 & 21.0 & 4.50 & -1.34 & 2.76 & 5.28 & 4.66 \\
\hline$<20 \%$ & -30.7 & 19.3 & 4.66 & 0.61 & 2.21 & 5.16 & 4.67 \\
\hline$>20 \%$ & -28.2 & 21.0 & 4.16 & -0.88 & 3.62 & 5.51 & 4.70 \\
\hline SRTM & -37.0 & 47.0 & 2.74 & 0.79 & 6.99 & 7.51 & 4.03 \\
\hline
\end{tabular}

Table 4. Statistics obtained using difference DEM (TanDEM-X Jan 29, 2012 - LFDC) for Godavari test area.

\begin{tabular}{|l|l|l|l|l|l|l|l|}
\hline $\begin{array}{l}\text { Ref.Data } \\
\text { type }\end{array}$ & Min & Max & Mean & Skew & $\begin{array}{l}\text { Std } \\
\text { dev }\end{array}$ & RMSE & $\begin{array}{l}90 \% \\
\text { RMSE }\end{array}$ \\
\hline LFDC & -34.3 & 15.4 & -0.60 & -1.45 & 2.57 & 2.64 & 1.43 \\
\hline$<20 \%$ & -34.2 & 15.4 & -0.57 & -1.98 & 1.98 & 2.06 & 1.08 \\
\hline$>20 \%$ & -34.3 & 14.9 & 4.16 & -0.67 & 4.05 & 4.10 & 2.87 \\
\hline SRTM & -41.3 & 50.0 & -2.34 & 1.11 & 7.24 & 7.58 & 4.12 \\
\hline
\end{tabular}

Table 5. Statistics obtained using difference DEM (TanDEM-X July 4, 2011 - LFDC) for Godavari test area. 


\begin{tabular}{|l|l|l|l|l|l|l|}
\hline $\begin{array}{l}\text { Ref.Data } \\
\text { type }\end{array}$ & Min & Max & Mean & Skew & $\begin{array}{l}\text { Std } \\
\text { dev }\end{array}$ & RMSE \\
\hline $\begin{array}{l}\text { LFDC } \\
\text { (413 pts })\end{array}$ & -7.9 & 15.6 & 2.68 & 0.69 & 3.09 & 4.09 \\
\hline $\begin{array}{l}\text { ICESAT } \\
(1887 p t s)\end{array}$ & -13.5 & 15.6 & 2.17 & 0.70 & 2.73 & 3.49 \\
\hline $\begin{array}{l}\text { SRTM } \\
(1887 p t s)\end{array}$ & -28.0 & 40.8 & 0.03 & 0.87 & 4.31 & 4.31 \\
\hline
\end{tabular}

Table 6. Statistics of difference between TanDEM-X DEM and reference data sets with selected point data.

Elevation profiles in $\mathrm{X}$ - and $\mathrm{Y}$-direction for this test area is given in Figure 7. TanDEM-X DEM follows the trend of LFDC DEM. LFDC elevation in X-profile is lower by $5 \mathrm{~m}$ in flat areas with spikes due to vegetation. Peaks in $\mathrm{X}$ - and $\mathrm{Y}$ - profiles match very well indicating both the DEMs represents the same pixel.

\subsection{DEM for Open-pit Coal Mine Area}

From the full image of TanDEM-X DEM data, coal mine area is separated and shown in Figure 8 for both ascending and descending passes data. The statistics from difference image with descending pass TanDEM-X DEM is given in Table 7. From Figure 8, the changes are seen at left part where light yellow colour in Figure 8(a) became red (increase in height) in Figure 8(b) due to dumping of debris from mine and at upper right corner, light green colour in Figure 8(a) became light blue (decrease in height) in Figure 8(b) due to mining activity from 2012 to 2013. SRTM 90 m DEM obtained in Feb. 2000 is also shown for comparison. Many changes can be seen over 13 year duration. The range of DEM values in SRTM DEM is $-50 \mathrm{~m}$ to $112 \mathrm{~m}$, whereas the range from TanDEM-X DEM in 2013 is $-147 \mathrm{~m}$ to $186 \mathrm{~m}$. Further evaluation of DEM is to be done using groundtruth with DGPS.

A significant change is seen through $\mathrm{X}$ - and $\mathrm{Y}$-profile of various DEMs over this area as shown in Figure 9. Location with no change among the DEMs at particular point is due to no mining activity in this area. The LFDC DEM and TanDEM-X DEM in 2013 follow the same trend with less difference. The large height ambiguity in TanDEM-X DEM of 2013 and steep slopes in this area may be investigated further.

\section{CONCLUSIONS}

TanDEM-X raw DEMs have been generated for two test areas of India and compared with highly accurate airborne LiDAR, photogrammetry and ICEsat elevation data. Even with flat areas of Bihar test area, RMSE of $5 \mathrm{~m}$ is observed as we have used raw DEMs for comparison. But it is better than the specified limit of TanDEM-X mission specification i.e. $10 \mathrm{~m}$. In moderately hilly terrain area of Godavari too, similar accuracy is obtained. DEM with slopes greater than $20 \%$ gives RMSE of $6 \mathrm{~m}$. The skewness value close to zero shows the normal distribution of error, indicating the high quality of TanDEM-X DEM in these areas. In the coal mine area, which is undergoing a continuous change, RMSE value is within $10 \mathrm{~m}$ when compared with LFDC reference data acquired during the same year as that of TanDEM-X data verifying its high quality. The performance of TanDEM-X DEM in more difficult terrain areas and densely vegetated areas needs to be evaluated based on highly accurate LiDAR DEM and DGPS data. However, such areas get severely affected by geometrical distortion and thus fused raw DEMs from several passes in the same year may be evaluated before the final global DEM is ready. Global DEM for difficult terrains are being generated by DLR using additional coverages with different baselines.
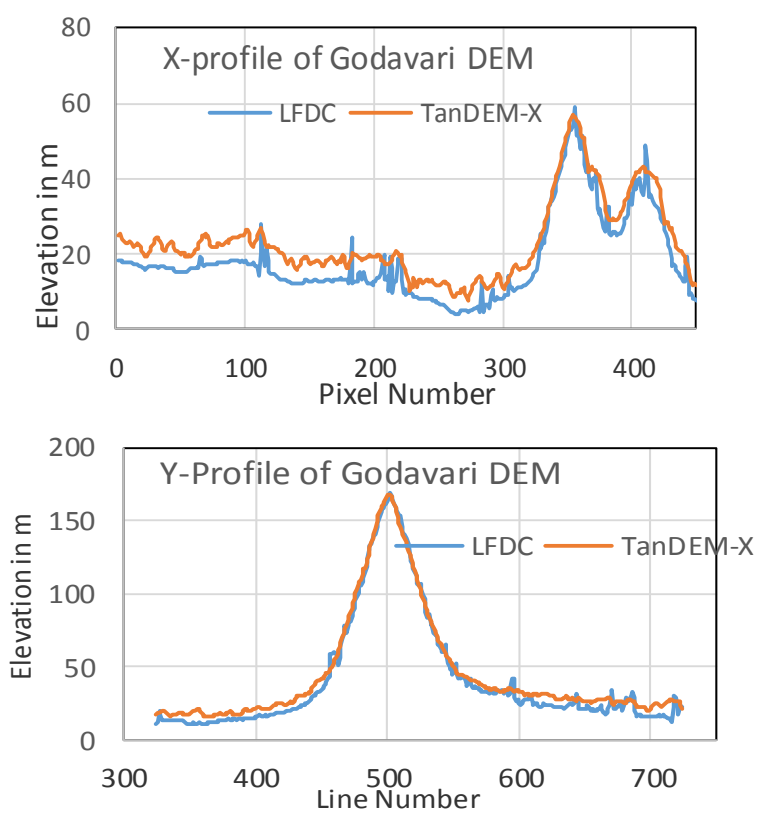

Figure 7. Elevation trend for aerial LFDC and TanDEM-X DEMs for Godavari test site at a particular location in X-and Y-direction of the image.

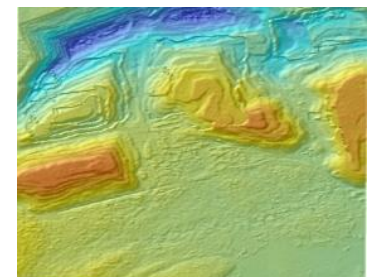

(a)

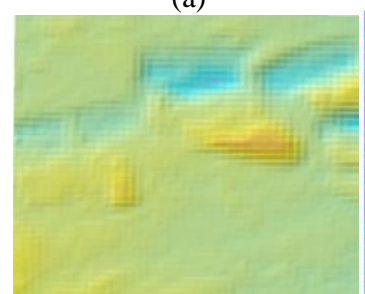

(c)

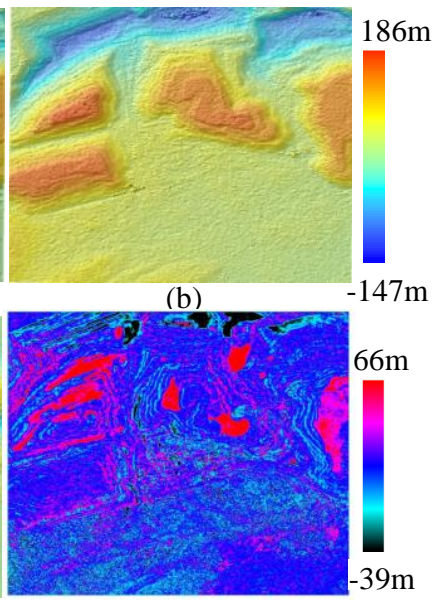

(d)
Figure 8. TanDEM-X DEM for open-pit coal mine area (a) DEM obtained on 05-09-2012 and (b) on 10-01-2013, (c) SRTM DEM and (d) Difference between TanDEM-X Jan. 10, 2013 and LFDC DEM. Colour scale is same for all DEMs.

\begin{tabular}{|l|l|l|l|l|l|l|l|}
\hline $\begin{array}{l}\text { Ref.Data } \\
\text { type }\end{array}$ & Min & Max & Mean & Skew & Std dev & $\begin{array}{l}\text { RMS } \\
\text { E }\end{array}$ & $\begin{array}{l}90 \% \\
\text { RMSE }\end{array}$ \\
\hline LFDC & -39.0 & 66.8 & 5.13 & 1.55 & 4.99 & 7.16 & 5.31 \\
\hline$<20 \%$ & -27.2 & 66.8 & 4.76 & 1.65 & 4.64 & 6.65 & 5.06 \\
\hline$>20 \%$ & -39.0 & 65.2 & 5.54 & 1.42 & 5.33 & 7.69 & 5.66 \\
\hline
\end{tabular}

Table 7. Elevation difference statistics for the coal mine area for Jan 10, 2013 TanDEM-X DEM. 

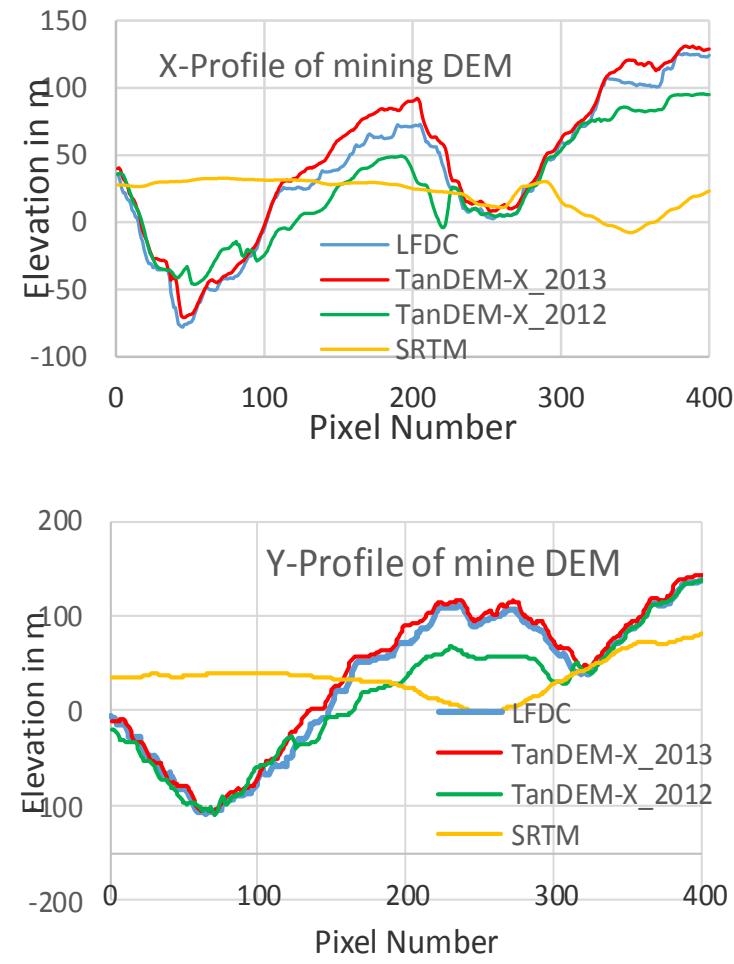

Figure 9. Elevation trend in X- and Y-direction of LFDC, TanDEM-X 2012, 2013 and SRTM DEMs.

\section{ACKNOWLEDGEMENTS}

We thank Dr. V. Jayaraman, former Director of NRSC for his advice to do the work. Thanks are also due to German Aerospace Centre (DLR), Germany for providing data under A.O. No. XTI_VEGE0635 and SARMAP for providing evaluation version of SARscape.

\section{REFERENCES}

Bamler, R., Eineder, M, Kampes, B., Runge, H., Adam, N., 2003. SRTM and beyond: Current situation and new developments in spaceborne SAR and InSAR. Proceedings of Joint Workshop of ISPRS Working Groups I/2, I/5, IC WG II/IV and EARSeL.

Bräutigam,B., Martone, M., Rizzoli, P., Bachmann, M., Krieger, G.,2012. Interferometric performance of TanDEM-X global DEM acquisitions. Proc. of 9th European Conference on Synthetic Aperture Radar (EUSAR), pp. 89-92.

Carlisle, B.H., 2002. Digital elevation model quality and uncertainty in DEM-based spatial modelling. $\mathrm{PhD}$ Thesis, University of Greenwich, London, UK.
González, J.H., Antony, J.M.W., Bachmann, M., Krieger, G., Zink, M., Schrank, D., Schwerdt, M., 2012. Bistatic system and baseline calibration in TanDEM-X to ensure the global digital elevation model quality. ISPRS Journal of Photogrammetry and Remote Sensing, 73, pp.3-11.

Gruber, A., Wessel, B., Huber, M., Roth, A., 2012a. Operational TanDEM-X DEM calibration and first validation results. ISPRS Journal of Photogrammetry and Remote Sensing, 73, pp. 39-49.

Gruber, A., Wessel, B., Huber, M., Breunig, M., Wagenbrenner, S., Roth, A., 2012b. Quality assessment of first TanDEM-X DEMs for different terrain types. Proc. of 9th European Conference on Synthetic Aperture Radar (EUSAR), pp.101104.

Hajnsek, I., Busche, T. E., 2010. TanDEM-X ground segment TD-PD-PL-0069, TanDEM-X Science Plan, pp. 28.

Krieger, G., Moreira, A., Fiedler, H., Hajnsek, I., Werner, M., Younis, M., Zink, M., 2007. TanDEM-X: A satellite formation for high-resolution SAR interferometry. IEEE Transactions on Geoscience and Remote Sensing 45 (11), pp. 3317-3341.

Massonnet D., Feigl K.L., 1998. Radar interferometry and its applications to changes in the Earth's surface. Review of Geophysics 36 (4), pp. 441-500.

Rosen P. A., Hensley S., Joughin I. R., Li F. K., Madsen S. N., Rodríguez E., and Goldstein R.M., 2000. Synthetic Aperture Radar Interferometry. Proceedings of the IEEE 88(3), pp 333382

Schulze, D., Bachmann, M., Braeutigam, B; Borla-Tridon, D., Rizzoli, P., Martone, M., Zink, M., Krieger, G., 2014. Status of TanDEM-X DEM Acquisition, Calibration and Performance. Proc. of 10th European Conference on Synthetic Aperture Radar (EUSAR), pp.1-4

Toutin, T. and Gray, L., 2000. State-of-the-art of elevation extraction from satellite SAR data. ISPRS Journal of Photogrammetry \& Remote Sensing, 55, 13-33.

Wechsler, S.P., 2007. Uncertainties associated with digital elevation models for hydrologic applications: A review. Hydrology and Earth System Sciences, 11, pp. 1481-1500.

Wechsler, S.P., 2003. Perceptions of digital elevation model uncertainty by DEM users, URISA Journal, 15(2), pp. 57-64.

Zhou, X., Ni-Bin, C., Li, S., 2009. Applications of SAR Interferometry in earth and environmental science research. Molecular Diversity Preservation International Publisher 9(3), pp. 1876-1912. 